\title{
PENERAPAN TEORI PERILAKU TERENCANA PADA MAHASISWA YANG TERGABUNG PADA KOMUNITAS KEWIRAUSAHAAN
}

\author{
Tri Siwi Agustina \\ Departemen Manajemen Fakultas Ekonomi dan Bisnis Universitas Airlangga \\ e-mail: siwi@feb.unair.ac.id.co
}

\begin{abstract}
The younger generation still had enough time to be able to determine the best career for their life, including being able to choose his career as an entrepreneur. This study focused on students belonging to the entrepreneurial community in the campus therefore an object of research is the students belonging to the entrepreneurial community WEBS and BETA at Airlangga University. This study uses Partial Least Square (PLS) as a statistical test to answer the problem formulation and testing hypotheses based on the study of theory and previous research. The sample used in this study using census sampling methods, which uses the entire population as a sample in the study. The samples used in the study were 80 students in the WEBS membership and BETA membership in Airlangga University. Method of data dissemination is done with a questionnaire during March until April, 2019. The result shows that (1) Educational support, subjective norm, and structural support directly influence the entrepreneurial intention; (2) Educational support and structural support indirectly influncing on entrepreneurial intention through attitude toward entrepreneurial behavior and perceived behavioral control; (3) Subjective norms indirectly influncing on entrepreneurial intention through attitude toward entrepreneurial behavior, but Subjective norms can't influencing entrepreneurial intention through perceived behavioral control.
\end{abstract}

Keywords: educational support, subjective norms, structural support, attitude toward entrepreneurial behavior, perceived behavioral control, entrepreneurial intention, student, student community

\section{PENDAHULUAN}

Entrepreneurship telah menjadi suatu hal yang menarik untuk diteliti sejak 1980-an. Entrepreneurship telah dianggap sebagai mesin pertumbuhan sosial ekonomi dengan memberikan kesempatan kerja dengan berbagai lapangan pekerjaan segala bidang pada penduduk (Reynolds et al., 2000) sehingga dapat membantu untuk mengatasi masalah seperti pengangguran yang tinggi (Wennekers dan Thurik, 1999).

Generasi muda masih punya cukup waktu untuk dapat menentukan karier yang terbaik bagi kehidupan mereka termasuk untuk dapat memilih kariernya sebagai seorang entrepreneur. Berbeda dengan penelitian-penelitian terdahulu tentang intensi wirausaha pada mahasiswa, penelitian ini difokuskan pada mahasiswa yang terga- bung pada komunitas kewirausahaan di dalam kampus. Tujuan penelitian ini adalah untuk mengetahui pengaruh langsung dan tidak langsung educational support, subjective norm, dan structural norm terhadap entrepreneurial intention melalui attitude toward entrepreneurial behavior pada mahasiswa yang terlibat pada komunitas kewirausahaan di kampus.

Kontribusi yang diharapkan dari penelitian ini adalah dapat mempertajam upaya pengembangan kewirausahaan di lingkungan kampus, terutama mengarahkan mahasiswa yang tergabung pada komunitas kewirausahaan agar kegiatan yang dilakukan selama mahasiswa lebih efektif mendukung pilihan karier mereka sebagai seorang wirausaha (entrepreneur).

Kata "kewirausahaan" diambil dari istilah entrepreneur yang berasal dari bahasa Prancis 
yaitu entre dan preneur yang berarti berusaha (Bird dan West, 1997). Seiring dengan perkembangan zaman, maka semakin banyak pula perkembangan mengenai definisi dari kewirausahaan.

Menurut Ajzen (1991), intensi adalah anteseden langsung dari perilaku. Ajzen menyatakan bahwa perilaku tidaklah dilakukan tanpa melalui proses berpikir, melainkan mengikuti suatu proses pemikiran yang melibatkan informasi yang relevan mengenai perilaku tersebut dan dapat diperkuat maupun diperlemah oleh peristiwa yang menyangkut perilaku tersebut.

Pada beberapa literatur terdahulu juga dibahas mengenai dampak dari contextual factors pada entrepreneurial intention. Türker dan Selçuk (2009) menganggap bahwa faktor kontekstual merupakan salah satu faktor yang penting dalam memprediksi niat kewirausahaan. Selanjutnya, Türker dan Selçuk (2009) juga mengembangkan entrepreneurial support model (ESM) yang terdiri dari: educational support, subjective norm, dan structural support

Educational support di universitas dideskripsikan oleh Türker dan Selçuk (2009) sebagai cara yang efisien untuk memperoleh pengetahuan mengenai kewirausahaan. Pengetahuan tersebut akan digunakan sebagai tahap awal bagi seorang individu dalam memulai suatu bisnis yang baru. Penelitian tersebut menghasilkan temuan bahwa pendidikan di universitas memiliki dampak positif pada niat kewirausahaan. Berdasarkan pernyataan teoretis tersebut maka dapat diturunkan hipotesis sebagai berikut.

H1: Educational support berpengaruh langsung terhadap entrepreneurial intention.

Entrepreneurship education berfokus pada mengembangkan generasi muda dengan minat (passion) serta multiple skills. Hal ini bertujuan untuk mengurangi risiko yang terkait dengan entrepreneurship dan membimbing seseorang menjadi sukses bermula dari tahap awal sampai tahap dewasa (Izedomi dan Okafor, 2010). Entrepreneurship education tidak hanya memberikan landasan teoretis mengenai konsep kewirausahaan tetapi membentuk sikap, perilaku, dan pola pikir menjadi seorang entrepreneur (Retno \& Trisnadi, 2012). Attitude Toward Entrepreneurship dalam penelitian Liao \& Welsch (2004), serta Kolvereid \& Isaksen (2006) mengemukakan tentang seberapa jauh seseorang berkomitmen dan mau berkorban menjadi wirausaha dibandingkan menjadi karyawan. Teori tersebut juga memprediksi bahwa semakin besar sikap dan norma subjektif terhadap perilaku, dikombinasikan dengan pengendalian diri yang kuat maka akan semakin besar pula minat akan melakukan perilaku tertentu. Dalam konteks ini yang dimaksud adalah untuk berwirausaha. Sikap kewirausahaan itu sendiri berupa kepercayaan diri, berinisiatif, memiliki motif berprestasi, memiliki jiwa kepemimpinan, berani mengambil risiko dengan penuh perhitungan (Suryana, 2006). Berdasarkan pernyataan-pernyataan teoretis tersebut maka dapat diturunkan hipotesis sebagai berikut.

H2: Educational support berpengaruh tidak langsung terhadap entrepreneurial intention melalui attitude toward entrepreneurship.

H3: Educational support berpengaruh tidak langsung terhadap entrepreneurial intention melalui perceived behavioral control.

Fishbein dan Ajzen (1975) mengemukakan bahwa subjective norm (norma subjektif) merupakan keyakinan individu mengenai harapan orang-orang sekitar yang berpengaruh baik secara perseorangan ataupun berkelompok untuk menentukan perilaku tertentu atau tidak. Terkait dengan entrepreneur intention maka subjective 
norms diartikan sebagai keyakinan individu mengenai harapan orang-orang sekitar yang berpengaruh baik secara perseorangan ataupun berkelompok dalam kaitannya dengan keterlibatan mereka dalam penciptaan nilai baru melalui tindakan inovatif, proaktif, dan berisiko (Fini et al., 2012). Berdasarkan pernyataan teori tersebut maka dapat diturunkan hipotesis sebagai berikut. H4: Subjective norm berpengaruh langsung terhadap entrepreneurial intention.

Turker dan Selcuk (2009) yang menyatakan bahwa keputusan dalam pemilihan karier pada seseorang akan dipengaruhi oleh keluarga dan teman-teman terdekat. Meskipun dalam penelitian Turker dan Selcuk tersebut tidak ditemukan hubungan yang signifikan antara subjective norm dengan entrepreneurial intention, namun penelitian Baumeister dan Vohs (1987) menyatakan bahwa subjective norm memiliki pengaruh pada entrepreneurial intention melalui attitude toward entrepreneur dan perceived behavior control.

Salah satu aturan yang berlaku secara umum dalam teori ini adalah makin favorable attitude dan subjective norms dan makin besar perceived behavioral control makin kuat intention seseorang untuk melakukan perilaku yang diusulkan. Berdasarkan pernyataan teori tersebut maka dapat diturunkan hipotesis sebagai berikut.
H5: Subjective norm berpengaruh tidak langsung terhadap entrepreneurial intention melalui attitude toward entrepreneurial behavior.

H6: Subjective norm berpengaruh tidak langsung terhadap entrepreneurial intention melalui perceived behavioral control.

Structural support dimaksudkan sebagai dukungan lingkungan eksternal untuk mendukung kegiatan kewirausahaan (Fini, Grimaldi, \& Sobero, 2009). Dukungan lingkungan eksternal tersebut adalah dukungan informasi, modal, infrastruktur dan jejaring usaha yang difasilitasi dari perguruan tinggi, instansi pemerintah, lembagalembaga keuangan mampu mendukung dan mempromosikan kegiatan kewirausahaan yang dilakukan. Berdasarkan pernyataan teori tersebut maka dapat diturunkan hipotesis sebagai berikut.

H7: Structural support berpengaruh langsung terhadap entrepreneurial intention.

Adanya dukungan lingkungan eksternal maka akan berpengaruh positif pada kendali seseorang untuk melaksanakan perilaku kewirausahaan, dan mempengaruhi rasa percaya diri mereka untuk berhasil ketika menerapkan perilaku kewirausahaan (Fini, Grimaldi, \& Sobero, 2009). Berdasarkan pernyataan teori tersebut maka dapat diturunkan hipotesis sebagai berikut.

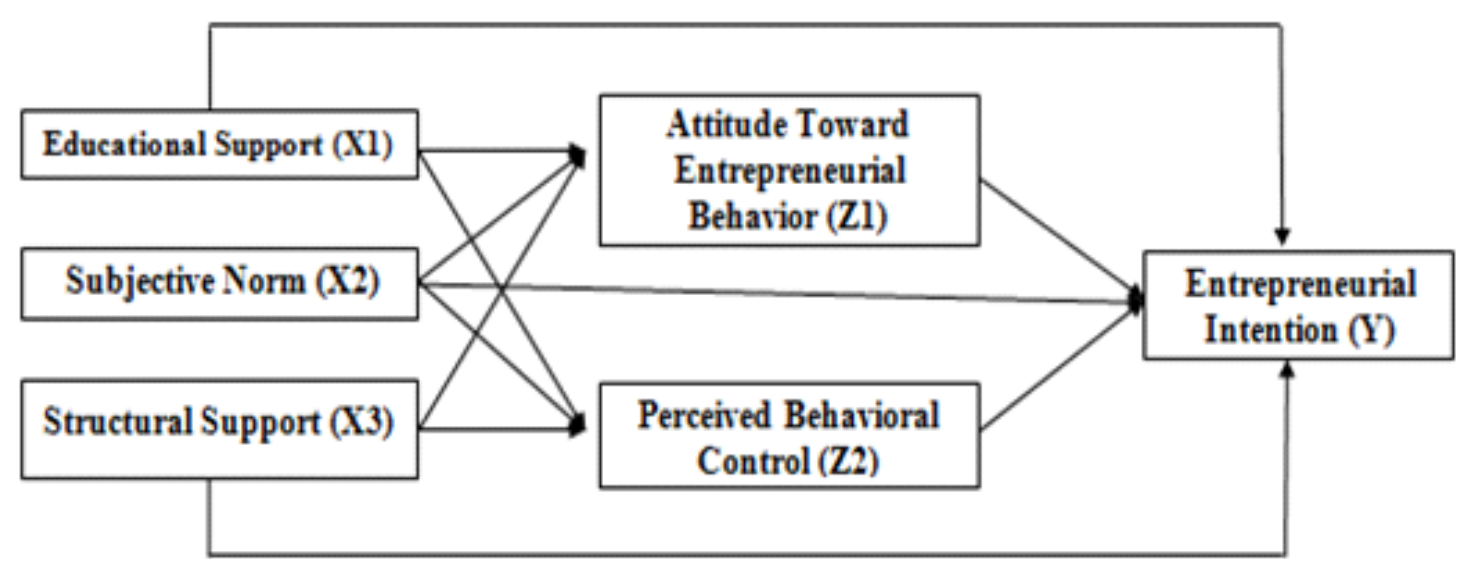

Gambar 1 Kerangka Berpikir 
H8: Structural support berpengaruh tidak langsung terhadap entrepreneurial intention melalui attitude toward entrepreneurial behavior.

H9: Structural support berpengaruh tidak langsung terhadap entrepreneurial intention melalui perceived behavioral control.

Hipotesis-hipotesis tersebut dapat dideskripsikan pada kerangka berpikir pada Gambar 1.

\section{METODE PENELITIAN}

Penelitian ini menggunakan partial least square (PLS) sebagai alat uji statistik untuk menjawab rumusan masalah dan menguji hipotesis yang telah dibuat berdasarkan kajian teori serta penelitian terdahulu.

Identifikasi variabel dinyatakan sebagai berikut educational support, subjective norm, dan structural support merupakan variabel dependen (X1, X2, dan X3), entrepreneurial intention merupakan variabel independen (Y). attitude toward entrepreneurship behavior sebagai variabel mediasi (Z1) dan perceived behavioral control sebagai variabel mediasi (Z2).

Populasi dari penelitian ini merupakan seluruh anggota komunitas kewirausahaan di lingkungan Universitas Airlangga yaitu WEBS dan BETA yang berjumlah 80 mahasiswa. Populasi ini dipilih karena pada anggota WEBS dan BETA tersebut sudah dibekali dengan pengalaman dan pemahaman mengenai entrepreneurship sehingga secara tidak langsung mereka telah memiliki pandangan terkait dengan hal tersebut dan pandangan tersebut yang akan menumbuhkan intensi kewirausahaan pada diri mereka. Sampel yang digunakan dalam penelitian ini menggunakan metode sampling jenuh (metode sensus), yang menggunakan seluruh populasi sebagai sampel dalam penelitian. Jumlah sampel yang digunakan dalam penelitian adalah 80 mahasiswa yang tergabung dalam keanggotaan WEBS dan BETA Universitas Airlangga.

Metode penyebaran data dilakukan dengan kuesioner selama 1 bulan (Maret-April 2019). Secara keseluruhan, semua instrumen variabel dependen dan independen berupa checklist dengan menggunakan 5 poin skala Likert (skala 1 = sangat tidak setuju hingga skala 5 = sangat setuju).

\section{HASIL DAN PEMBAHASAN}

WEBS dan BETA merupakan komunitas mahasiswa Unair yang memiliki minat untuk berwirausaha. Jika WEBS keanggotaannya hanya untuk mahasiswa Fakultas Ekonomi \& Bisnis, BETA keanggotaannya hanya untuk mahasiswa fakultas sains dan teknologi. Baik WEBS dan BETA berada di bawah koordinasi Badan Eksekutif Mahasiswa (BEM) fakultas masing-masing. Saat ini WEBS sudah memasuki tahun ke-13 dan BETA memasuki tahun ke-7 berkiprah dalam hal kewirausahaan mahasiswa dengan kegiatankegiatan yang berfokus pada pelatihan workshop, pameran hasil usaha, business visit, dan networking.

Hasil penyebaran 80 kuesioner pada responden maka didapatkan kuesioner yang kembali adalah sebanyak 67 mahasiswa (20 kuesioner yang kembali berasal dari anggota BETA dan 47 sisanya berasal dari anggota WEBS). Setelah diolah, didapatkan gambaran umum responden adalah sebagai berikut: sejumlah 36 mahasiswa adalah laki-laki $(53,7 \%)$ dan sisanya sejumlah 31 orang merupakan mahasiswa perempuan $(46,3 \%)$. Sebagian besar responden berusia berusia 21-23 tahun $(52,2 \%)$ dan sisanya berusia 19 sampai kurang dari 21 tahun sebanyak 32 
orang $(47,8 \%)$ Ditinjau dari pekerjaan orang tua, mayoritas orangtua responden tidak berlatar belakang sebagai wirausaha (39 orang atau $58,2 \%)$ dan sisanya 28 orang $(41,8 \%)$ mahasiswa memiliki orangtua yang berwirausaha. Selanjutnya, terkait dengan pengalaman menjalankan usaha mandiri (bisnis) sejumlah 40 mahasiswa yang menyatakan sudah menjalankan bisnis minimal 12 bulan (1 tahun), 18 mahasiswa menyatakan sudah menjalankan kurang dari 12 bulan dan sisanya 9 orang belum memulai menjalankan usaha mandiri.

Secara ringkas dijelaskan bahwa data yang diolah telah memenuhi syarat validitas, reliabilitas item kuesioner serta goodness-fit model yang dihasilkan dari analisis Smart PLS dan hasil uji koefisiensi parameter jalur. Peneliti akan melakukan pengujian hipotesis yang telah disusun sebelumnya. Pengujian hipotesis ini didasarkan pada nilai signifikansi $<0,05$ pada $p$ value. Jika nilai $p$-value kurang dari 0,05 maka terdapat pengaruh antar-variabel dan hipotesis diterima.

Hasil pengujian hipotesis $1, p$ value 0,000 $<0,05$ maka hipotesis 1 yang menyatakan bahwa educational support berpengaruh signifikan terhadap entrepreneurial intention dapat diterima mahasiswa yang tergabung pada WEBS dan BETA mayoritas mendapatkan mata kuliah kewirausahaan. Sisanya adalah mahasiswa yang tidak mendapatkan mata kuliah kewirausahaan, namun terdapat beberapa mata kuliah yang terintegrasi pada kewirausahaan di beberapa pertemuannya. Proses belajar mengajar (PBM) melalui mata kuliah Kewirausahaan maupun mata kuliah yang terintegrasi dengan kewirausahaan di UNAIR dirasakan oleh responden dapat memotivasi munculnya ide-ide kreatif, lebih berani untuk merealisasikan ide menjadi produk nyata, serta menilai bahwa pendampingan selama implementasi ide hingga pameran produk usaha dirasakan dapat merangsang munculnya entrepreneurial intention. Hasil penelitian ini mendukung studi yang dilakukan Türker dan Selçuk (2009) bahwa educational support di universitas merupakan sebagai cara yang efisien untuk memperoleh pengetahuan mengenai kewirausahaan. Pengetahuan tersebut akan digunakan sebagai tahap awal bagi seorang individu dalam memulai suatu bisnis yang baru.

Pengujian hipotesis 2 menghasilkan $p$ value $0,00<0,05$ maka hipotesis 2 yang menyatakan bahwa terdapat pengaruh langsung educational support terhadap entrepreneurial intention melalui attitude toward entrepreneurial behavior diterima. Oleh karena pengaruh mediasi dari attitude toward entrepreneurial behavior berbentuk mediasi mutlak (full mediasi) maka dapat diartikan bahwa untuk agar education support dapat lebih berpengaruh pada pembentukan minat berwirausaha mahasiswa yang tergabung pada komunitas kewirausahaan di kampus maka mutlak diperlukan komitmen dan mau berkorban menjadi wirausaha dibandingkan menjadi karyawan. Bergabung pada komunitas kewirausahaan di kampus seperti WEBS dan BETA merupakan salah satu bentuk komitmen terhadap kewirausahaan.

Pengujian hipotesis 3 menghasilkan bahwa $p$ value $0,00<0,05$ sehingga hipotesis $3 \mathrm{di}-$ terima, hal tersebut dapat dimaknai bahwa $E d u$ cational support, berpengaruh tidak langsung terhadap entrepreneurial intention melalui perceived behavioral control. Oleh karena pengaruh mediasi dari perceived behavioral control berbentuk mediasi mutlak (full mediasi) maka dapat diartikan bahwa untuk agar education support dapat lebih berpengaruh pada pembentukan minat berwirausaha mahasiswa yang tergabung pada komunitas kewirausahaan di kampus maka 
mutlak diperlukan persepsi dari mahasiswa itu sendiri tentang kemudahan atau kesulitan untuk berwirausaha. Sama halnya dengan pembahasan tentang hasil hipotesis 3 bahwa dukungan pendidikan kewirausahaan saja dirasakan belum cukup untuk membentuk minat wirausaha. Oleh karena itu, bergabung pada komunitas kewirausahaan di kampus seperti WEBS dan BETA merupakan salah satu cara mahasiswa untuk mengarahkan persepsi mereka tentang kemudahan dan kesulitan yang dihadapi terkait dengan minat mereka untuk berwirausaha. Pembuktian attitude toward entrepreneurship dan perceived behavioral control sebagai mediasi pada pengaruh education support pada Intention to be entrepreneur pada penelitian ini mendukung penelitian Liao dan Welsch (2004) dan Kolvereid dan Isaksen (2006).

Pengujian hipotesis 4 mendapatkan hasil $p$ value $0,000<0,05$ maka hipotesis 4 diterima sehingga dapat diartikan bahwa terdapat pengaruh langsung subjective norm terhadap entrepreneurial intention. Norma subjektif dalam penelitian ini merepresentasikan keyakinan mahasiswa yang tergabung pada komunitas kewirausahaan tentang harapan orang-orang sekitar yang berpengaruh baik secara perseorangan ataupun berkelompok dalam kaitannya dengan aktivitas mereka dalam penciptaan nilai baru melalui tindakan inovatif, proaktif, dan berisiko. Oleh karena objek penelitian adalah mahasiswa maka orang-orang sekitar yang berpengaruh adalah orang tua. Semakin tinggi dukungan orang tua terhadap aktivitas kewirausahaan yang mereka lakukan, maka semakin tinggi minat untuk berwirausaha. Demikian sebaliknya, semakin berkurang dukungan orang-orang di sekitarnya terhadap aktivitas kewirausahaan yang mereka lakukan maka semakin berkurang minat untuk berwirausaha. Apabila dikaitkan dengan latar bela- kang orang tua responden yang mayoritas $(58,2 \%)$ tidak berlatar belakang wirausaha, dan dihubungkan dengan mean norma subjektif yang tinggi dapat diartikan bahwa para minat berwirausaha mahasiswa yang tergabung pada komunitas kewirausahaan di kampus seperti WEBS dan BETA dipengaruhi oleh dukungan orang tua terhadap aktivitas mereka untuk berwirausaha selama masa kuliah. Terkait dengan hasil tersebut, dan dihubungkan dengan hampir seimbangnya proporsi orang tua yang berlatar belakang sebagai wirausaha dengan yang tidak memiliki latar belakang sebagai wirausaha dapat dimaknai bahwa saat ini tampaknya mulai ada pergeseran harapan orang tua terhadap anak-anaknya dari menjadi karyawan ke wirausaha. Bagi mahasiswa yang orang tuanya berlatar belakang wirausaha, minat mereka untuk wirausaha dibangun karena adanya contoh (role model) orang tuanya.

Pengujian hipotesis 5 menunjukkan bahwa $p$ value $0,01<0.05$ maka hipotesis 5 yang menyatakan bahwa terdapat pengaruh langsung subjective norm terhadap entrepreneurial intention melalui attitude toward entrepreneurial behavior dapat diterima. Oleh karena pengaruh mediasi dari attitude toward entrepreneurial behavior terhadap subjective norm terhadap entrepreneurial intention berbentuk mediasi mutlak maka dapat diartikan bahwa agar dukungan orang tua terhadap minat wirausaha anaknya dapat optimal maka diperlukan adanya komitmen dari mahasiswa yang tergabung dalam komunitas kewirausahaan kampus. Orang tua menuntut komitmen yang tinggi terkait dengan pilihan anaknya di masa depan untuk berwirausaha karena adanya kekhawatiran orang tua pada waktu, tenaga, dan pikiran yang diberikan orang tua pada anak yang mulai merintis usaha selama kuliah, karena dikhawatirkan akan tidak fokus pada kuliah. 
Pengujian hipotesis 6 menghasilkan $p$ value $0,527<0.05$ sehingga hipotesis 6 ditolak, hasil tersebut menunjukkan bahwa variabel subjective norms tidak berpengaruh terhadap entrepreneurial intention melalui perceived behavioral control. Hal tersebut dapat dimaknai bahwa keyakinan untuk dapat berhasil sebagai wirausaha di masa mendatang dengan menerima segala risiko kemudahan dan kesulitan dalam merintis usaha di masa kuliah tidak dapat mendukung pengaruh dukungan dari orang-orang sekitar terhadap minat untuk berwirausaha. Hal tersebut tidak terlepas dari suatu kondisi bahwa orang tua masih belum dapat melihat secara nyata bahwa keputusan anaknya merintis usaha mandiri saat kuliah belum dapat mendatangkan keuntungan baik secara ekonomis dan sosial. Orang tua masih memiliki anggapan bahwa yang dilakukan oleh anaknya adalah sebagai proses pembelajaran untuk menjadi wirausaha.

Pengujian hipotesis 7 menghasilkan $p$ value $0,038<0.05$ maka hipotesis diterima, yang artinya variabel structural support memiliki pengaruh yang signifikan pada entrepreneurial intention. Bentuk dukungan terbesar yang diterima oleh anggota WEBS maupun BETA adalah diizinkannya komunitas mahasiswa yang memiliki minat kewirausahaan berlangsung di lingkungan Unair. Dengan adanya komunitas tersebut, keinginan mahasiswa untuk menjalani proses kewirausahaan selama kuliah dapat tersalurkan. Selain itu, Unair juga melakukan pembinaan terpusat tentang kewirausahaan di bawah naungan PPKK (Pusat Pembinaan Karier dan Kewirausahaan) Unair, di mana program nya melakukan pembinaan kewirausahaan mahasiswa berupa pelatihan-pelatihan, workshop, mentoring, dan gathering dengan alumni yang telah sukses sebagai wirausaha. PPKK pun juga memberikan dukungan penuh pada WEBS dan BETA.
Di sisi lain program-program kewirausahaan lain seperti PKM, lomba bisnis plan, KBMI serta kompetisi yang diselenggarakan perbankan atau BUMN sangat berperan dalam mendorong munculnya keinginan untuk berwirausaha.

Pengujian hipotesis 8 menunjukkan bahwa p value $0,002<0,05$ maka hipotesis ke-8 yang menyatakan bahwa terdapat pengaruh langsung structural support terhadap entrepreneurial intention melalui attitude toward entrepreneurial behavior dapat diterima. Pengaruh dukungan struktural akan semakin nyata terhadap entrepreneur intention apabila disertai dengan persepsi bahwa menjadi wirausaha lebih bermanfaat bagi dirinya di masa depan. Manfaat tersebut menjadi motivasi (faktor pendorong) seseorang akan menekuni profesi sebagai entrepreneur sebagai pilihan kariernya. Bentuk motivasi yang dimaksud dapat berupa kebebasan dalam bertindak, kebebasan dalam mengambil keputusan, penghasilan yang lebih tinggi, aktualisasi diri dan kemandirian.

Hasil pengujian hipotesis 9 menunjukkan bahwa $p$ value $0,02<0,05$ maka hipotesis 9 diterima, artinya variabel Structural support berpengaruh tidak langsung terhadap entrepreneurial intention melalui perceived behavioral control. Pengaruh dukungan struktural akan semakin nyata terhadap entrepreneur intention apabila disertai dengan keyakinan yang kuat untuk menjadikan entrepreneur sebagai pilihan kariernya. Seperti telah diuraikan pada pembahasan tentang hipotesis 7 bahwa dukungan struktural yang terintegritas dari Universitas Airlangga, instansi pemerintah, lembaga keuangan berupa pendampingan usaha, modal, akses informasi, dan jaringan usaha selama kuliah menimbulkan keyakinan yang tinggi bagi responden untuk dapat memanfaatkan peluang atau mengatasi kendala dalam berwirausaha dan hal tersebut 
berdampak pada pilihannya untuk berwirausaha sebagai kariernya setelah lulus kuliah.

\section{KESIMPULAN}

Berdasarkan rumusan masalah yang diajukan, hipotesis, hasil dan pembahasan, diperoleh kesimpulan sebagai berikut.

1. Educational support, subjective norm, dan structural support berpengaruh langsung terhadap entrepreneurial intention.

2. Educational support, dan structural support berpengaruh tidak langsung terhadap entrepreneurial intention melalui attitude toward entrepreneurial behavior dan perceived behavioral control.

3. Subjective norms berpengaruh tidak langsung terhadap entrepreneurial intention melalui attitude toward entrepreneurial behavior, namun subjective norms tidak berpengaruh terhadap entrepreneurial intention melalui perceived behavioral control.

\section{DAFTAR RUJUKAN}

Ajzen, I. (1991). The Theory of Planned Behavior. Organizational Behavior and Human Decision Processes.

Astuti, R. D. \& Martdianty, F. (2012). “Student's Entrepreneurial Intentions by Using Theory of Planned Behavior", The Case in Indonesia." The South East Asian Journal of Management 6.2: 100.

Astuti, R. D. \& Martdianty, F. (2012). “Students' Perception and Intention toward Entrepreneurship: Development of Planned Behavior Entrepreneurial Model on Six State Universities in Indonesia." International Conference on Enterprise Marketing and Globalization (EMG). Proceedings. Global Science and Technology Forum.
Bird, B. (1988). Implementing Entrepreneurial Idea: The Case for Intention. Academy of Management Review.

Bird, B. J. \& west, G. P. (1997). Time and Entrepreneurship. Entrepreneurship Theory and Practice, 22: 5-9.

Boyd, Nancy G. \& George S. Vozikis. (1994). "The influence of self-efficacy on the development of entrepreneurial intentions and actions." Entrepreneurship theory and practice 18, 63-63. (online) (diakses pada 16 Mei 2015, pukul 09:20) (wwww.scholar. google.com).

Bullough, Amanda, Maija Renko, \& Tamara Myatt. (2014), "Danger zone entrepreneurs: The importance of resilience and self efficacy for entrepreneurial intentions." Entrepreneurship Theory and Practice 38.3: 473-499.

Denanyoh, Richard, Kwabena Adjei, \& Gabriel Effah Nyemekye. (2015). "Factors That Impact on Entrepreneurial Intention of Tertiary Students in Ghana." International Journal of Business and Social Research 5.3: 19-29.

Fayolle, Alain (Ed.). (2007). Handbook of Research in Entrepreneurship Education Vol. 2. Britain: MPG Books Ltd.

Fini, Riccardo. (2012). "The determinants of corporate entrepreneurial intention within small and newly established firms." Entrepreneurship Theory and Practice 36.2: 387-414.

Franke, Nikolaus \& Christian Lüthje. (2004). "Entrepreneurial intentions of business students-A benchmarking study." International Journal of Innovation and Technology Management 1.03: 269-288.

Galloway. L, Kelly. S., \& Keogh. W. (2006). Identifying Entrepreneurial Potential in 
Students. Working Paper No. 006, National Council for Graduate Entrepreneurship.

Gerry. C, Susana. C., \& Nogueira. F. (2008). Tracking Student Entrepreneurial Potential: Personal Attributes and the Propensity for Business Start-Ups after Graduation in a Portuguese University. International Research Journal Problems and Perspectives in Management, 6(4): 45-53.

Ghazali, I. 2008. Structural Equation Modelling (SEM) metode alternative dengan Partial Least Square. Badan Penerbit Universitas Diponegoro Semarang.

Gurbuz, G. \& Aykol, S. (2008). Entrepreneurial Intention of Young Educated Public in Turkey. Journal of Global Strategic Management, 4(1): 47-56.

Hair, J. F., et al. (1998). Multivariate Data Analysis. (Edisi 5). New Jersey: McGrawHill International Edition.

Jones, C., English, J. (2004). “A Contemporary Approach to Entrepreneurship Education" Education + Training, Vol. 46, Iss: 8/9, pp. 416-423.

Kadir, Mumtaz Begam Abdul, Munirah Salim, and Halimahton Kamarudin. (2012). "The relationship between educational support and entrepreneurial intentions in Malaysian higher learning institution." ProcediaSocial and Behavioral Sciences 69: 21642173.

Karimi, Saeid et al. (2013). "Understanding role models and gender influences on entrepreneurial intentions among college students." Procedia-Social and Behavioral Sciences 93, 204-214.

Kidwell, Blair \& Robert D. Jewell. (2003). "An examination of perceived behavioral control: internal and external influences on intention." Psychology \& Marketing 20.7: 625-642.

Kolvereid \& Isaksen. (2005). New business start-up and subsequent entry into selfemployment. Journal of Business Venturing 21 (6), (2006) 866-885, doi: 10.1016/ j.jbusvent.,.06.008

Liao, J. \& Welsch, H. (2004). Entrepreneurial Intensity. In W.B. Gartner, K.G. Shaver, N.M. Carter, \& P.D. Reynolds (Eds). Handbook of Entrepreneurial Dynamics. Thousand Oaks, CA: Sage.

Linan, F. \& Chen, Y. W. (2009). Development and Cross-Cultural Application of a Specific Instrument to Measure Entrepreneurial Intentions. Entrepreneurship Theory o Practice, 33(3), 593-617.

Liñán, Francisco, Juan Carlos Rodríguez-Cohard, \& José M. Rueda-Cantuche. (2011) "Factors affecting entrepreneurial intention levels: a role for education." International Entrepreneurship and Management Journal 7.2, 195-218.

Liñán, F. \& Rodríguez, J. C. (2004). “Entrepreneurial attitudes of Andalusian University students", 44th ERSA Conference, Porto (Portugal), 21-25 august.

Longenecker G. Justin, dkk. (2001). Kewirausahaan Manajemen Usaha Kecil. Jakarta: Salemba Empat.

Lüthje, Christian \& Nikolaus Franke. (2003). “The 'making' of an entrepreneur: testing a model of entrepreneurial intent among engineering students at MIT." Rod Management 33.2: 135-147.

Morris, M. \& Lewis, P. (1995). The determinants of Entrepreneurial Activity. European Journal of Marketing, 29(7): 31-48.

Nilson, A., Borgstede, C. V., \& Biel, A. (2004). Willingness to Accept Climate Change 
Strategy: The Effect Values and Norms. Journal of environmental psychology, 24, 3, 267-277.

Romero, Isidoro, et al. (2011). Universities as suppliers of entrepreneurship education services. The cases of the university of Seville and the academy of economic studies in Bucharest. Amfiteatru Economic, 13.30: 347-361.

Schwarz, Erich J., et al. (2009). "The effects of attitudes and perceived environment conditions on students' entrepreneurial intent: An Austrian perspective." Education + Training, 51.4: 272-291.

Suryana. (2006). Kewirausahaan Usaha Pedoman Praktis: Kiat dan Proses Menuju Sukses, Edisi Ketiga. Jakarta: Penerbit Salemba.

Torres, José Luis Neri \& Warren Watson. (2013). "An examination of the relationship between manager self-efficacy and entrepreneurial intentions andperformance in mexican small businesses." Contaduría y Administración 58.3: 65-87.
Turker, Duygu \& Senem Sonmez Selçuk. (2009). "Which factors affect entrepreneurial intention of university students?" Journal of European Industrial Training 33.2: 142159.

Yurtkoru, E. Serra, Pýnar Acar, \& Begüm Seray Teraman. (2014). "Willingness to take risk and entrepreneurial intention of university students: An empirical study comparing private and state universities." ProcediaSocial and Behavioral Sciences, 150: 834840.

Yurtkoru, E. Serra, Zeynep Kabadayý Kupcu, \& Ahmet Doðanay. (2014). "Exploring the antecedents of entrepreneurial intention on Turkish university students." ProcediaSocial and Behavioral Sciences 150: 841850.

Zain, Rozihana Shekh et al. (2009). Entrepreneurial Intention among Malaysian Undergraduates. International Journal of Business and Management Vol. 4, No. 